plenary/invited talks. His total number of citations exceeds 17,000 and h-index is 63 as of Nov. 2010.

Kathryn J. Wahl heads the Molecular

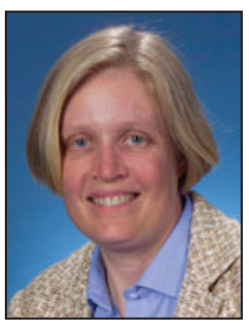
Interfaces and Tribology Section at the Naval Research Laboratory. Her research has focused on fundamental physics and chemistry of sliding and adhesive interfaces, both at macroscopic and nanometer scales. Currently, her research efforts include the development of in situ chemical and mechanical methods to probe bioadhesive contacts created by marine biofoulants like barnacles. Wahl received a BA degree in physics and mathematics from St. Olaf College in 1987, and a PhD degree in materials science and engineering from Northwestern University in 1992. Since then, she has been at the Naval Research Laboratory, first as a postdoctoral researcher and then as a research staff member in the Chemistry Division since 1995. She was a guest editor of the December 2008 issue of the MRS Bulletin on "In Situ Tribology." She serves on the editorial boards of the journals Wear, Tribology Letters, and Journal of Physics D, received a Navy Meritorius Civilian Service Medal in 2008, and is a Fellow of the American Vacuum Society (AVS) and Society of Tribologists and Lubrication Engineers.

\title{
MRS Bulletin volume organizers guide technical theme topics for 2012
}

\author{
www.mrs.org/bulletin
}

T he MRS Bulletin 2012 volume organizers, who will guide the development of theme topics for the 2012 volume year, are Lei Jiang (Chinese Academy of Sciences), Sergei V. Kalinin (Oak Ridge National Laboratory), Stéphanie P. Lacour (Ecole Polytechnique Fédérale de Lau-

\section{MRS} sanne), and Steven C. Moss (Aerospace Corporation). Requests for instructions on submitting proposals for MRS Bulletin theme topics can be e-mailed to bulletin@mrs.org.

Lei Jiang is currently a professor at the Institute of Chemistry, Chinese Academy of Sciences (ICCAS), and dean

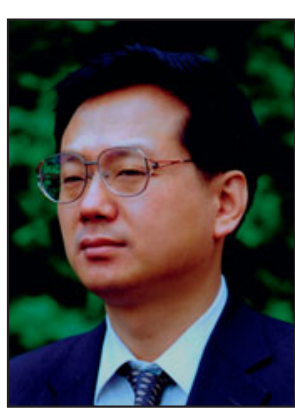
of the School of Chemistry and Environment, Beijing University of Aeronautics and Astronautics. His scientific interest is focused on bio-inspired surface and interfacial materials. Jiang received his BSc (1987), MSc (1990), and PhD (1994) degrees from Jilin University of China. He then worked as a postdoctoral fellow in
Tokyo University. In 1996, he worked as a senior researcher in Kanagawa Academy of Sciences and Technology. He joined ICCAS as part of the Hundred Talents Program in 1999. In 2009, he was elected academician of the Chinese Academy of Sciences.

Jiang has published one book, three book chapters, and more than 300 SCI journal articles His entire publications have been cited for over 7600 times. The h-index of his citations is 42 . He is the Asian Editor of Solid State Sciences, and a member of the Editorial Board of Advanced Functional Materials, Langmuir, Small, Biomicrofluidics, and Nano Research. Jiang is a visiting professor at Drexel University (USA), and part-time professor of Peking University (China) and Jilin University (China). He has received the National Natural Science Award of China (2nd grade, 2005).

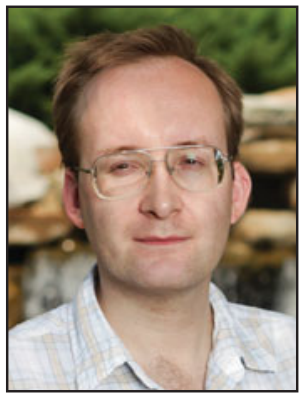

Sergei V. Kalinin is currently a senior research staff member at Oak Ridge $\mathrm{N}$ a t i o n a 1 Laboratory and co-theme leader for scanning probe microscopy at the Center for Nanophase Materials Sciences at ORNL (since 2007), following an Eugene P. Wigner fellow appointment at ORNL (2002-2004). He is also adjunct faculty at Pennsylvania State University and adjunct associate professor at the Department of Materials Sciences and Engineering at the University of Tennessee, Knoxville. His research is focused on the polarization and ionic and electronic transport and local bias-induced phase transitions in ferroelectrics, multiferroics, and energy storage and conversion materials, as well as molecular systems. The key element of his work is scanning probe microscopy (SPM) of electromechanical and transport phenomena, with specific emphasis of multidimensional and artificial-intelligence-assisted SPM methods. Kalinin received his $\mathrm{PhD}$ degree in materials science at the University of Pennsylvania in 2002. During his academic career, he has been the recipient of the Presidential Early Career Award for Scientists and Engineers (2009), Burton Medal of American Microscopy Society (2010), IEEETUFFC Young Investigator Award (2010), the Robert L. Coble (2009) and Ross Coffin Purdy (2003) Awards of American Ceramics Society, AVS Peter Mark Memorial Award (2008), and two R\&D100 awards (2010 and 2008), as well as Wigner Fellowship of Oak Ridge National Laboratory. He is the author of more than 180 scientific papers and 14 patents and patent disclosures on different aspects of SPM and ferroelectric 
materials applications. Several of his developments has been adopted and licensed by the SPM industry. He has organized an international workshop series on piezoresponse force microscopy and SPM for energy storage materials.

Stéphanie P. Lacour is an assistant professor at the Institute of Microengineering at EPFL (Ecole Polytechnique Fédérale de Lausanne) in Switzerland.

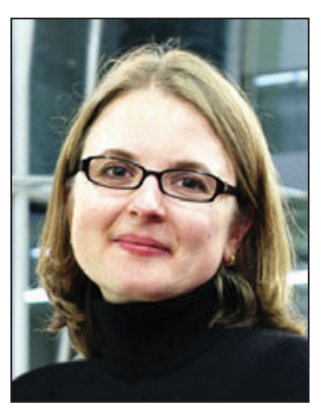

Her research

focuses on interfacing electronic devices with the human bodyfrom neural interfaces to conformable s k in - 1 i k e electronics. She holds an MS degree in microelectronics (1998) and a $\mathrm{PhD}$ degree in electrical engineering (2001) from INSA de Lyon, France. Between 2001 and 2005, she was a postdoctoral research associate in the Department of Electrical Engineering at Princeton University. Her research focused on the technology of inorganic thin-film electronics on flexible and elastomeric substrates, and the fabrication of stretchable micro-electrode arrays to study in vitro brain trauma. In 2006, she joined the University of Cambridge to coordinate a multidisciplinary team composed of engineers, material sci- entists, biologists, and neurosurgeons to develop a reliable and long-term polymeric neuroelectronic interfaces for peripheral nerve repair. In October 2007, she was awarded a University Research Fellowship from the Royal Society and headed the Stretchable Bioelectronics group at the Nanoscience Centre in Cambridge. She is the recipient of the 2006 MIT Technology Review TR35 award for her pioneering work on stretchable electronics. She is a fellow in Engineering at King's College, Cambridge. She is a co-organizer of a now yearly international symposium on compliant and stretchable electronics at the Materials Research Society Meetings (since 2006).

Steven C. Moss is director of the Microelectronics Technology Department at The Aerospace Corporation

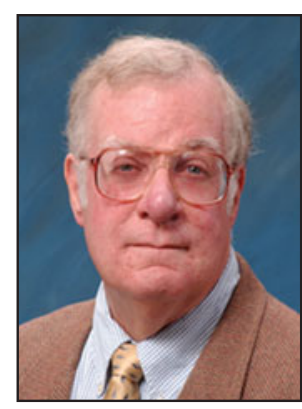
in Los Angeles, Calif. $\mathrm{He}$ manages a group of 30 35 staff members involved in research on microelectronic and optoelectronic device physics, radiation effects in materials and devices, reliability of microelectronic and optoelectronic devices, physics of failure, failure analysis, and destructive physical analysis including electron microscopy at the nanoscale and atomic scale. Moss received his BS degree with majors in physics and mathematics from Arkansas A\&M College in 1970, his MS degree in physics from Purdue University in 1972, and his $\mathrm{PhD}$ degree in physics from North Texas State University in 1981. He served a postdoctoral research associateship at the Naval Research Laboratory, and he took a position as a Visiting Assistant Professor with the Center for Applied Quantum Electronics at North Texas State University in 1982. He then joined the Aerospace Corporate two years later and attained his current position in 2002. Moss is a member of several professional societies including the Materials Research Society. At MRS, he has served on numerous committees, including chair of the Electronic Services Committee (1999-2000), the Information Services Committee (2003-2005), Library Advisory Board (2007-2010). Moss has also served on the Editorial Board of MRS Bulletin (1997-2010), where his principal responsibility has been the Research/Researchers section of the Bulletin. He has also served as an editor for several MRS Proceedings Volumes. In 2001, Moss was recognized by MRS as Volunteer of the Year (along with David B. Poker). In 2003, Moss was awarded the C. W. "Woody" White Award by the MRS in recognition of his volunteer service.

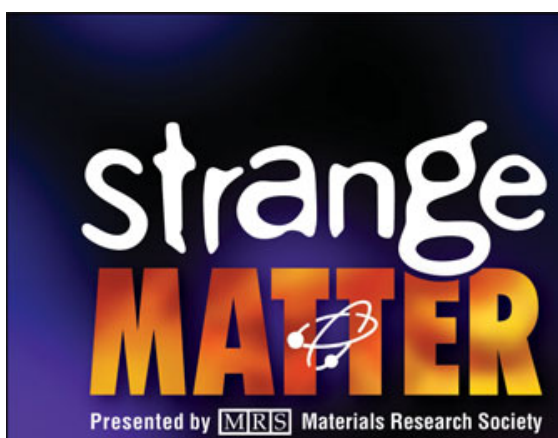

www.strangematterexhibit.com

\section{FAMILY FUN!}

Visit these science centers to experience the fascinating, practical, occasionally bizarre and often beautiful world of materials science:

+ Museo Modelo de Ciencias e Industria: MUMCI Toluca, Mexico, February-August 2011

+ Mid-America Museum

Hot Springs, Arkansas, June-August 2011

+ Museum of Science and Industry

Jacksonville, Florida, October 2011-April 2012

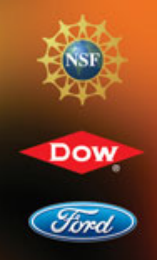

RioTintoAlcan

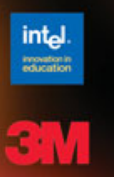


